\title{
Research on the influence of the component of biofuel on RP-3 jet fuel by laser test methods
}

\author{
Jianghong $\mathrm{Li}^{1, \mathrm{a}}$ \\ ${ }^{1}$ School of Power and Energy, Beihang University, Beijing 100191, China; \\ a541602013@qq.com
}

Keywords: Alternative Biofuel, atomization and spray, laser test methods

\begin{abstract}
The alternative biofuel allure our increasingly attention due to the shortage of traditional fossil fuel, so it's necessary for us to research the availability of alternative fuel. In our research, we focus on the usage of alternative fuel of the aircraft engine. For the purpose of safety, the common usage of alternative fuel is to blend it into traditional RP-3 fuel to accomplish all kinds of testing work. For there are many kinds of chemical compound in alternative fuel, so the common practice is to test every individual compound to justify the atomization and combustion characters of alternative fuel. In this work, we blend the alkane C17 and C18 to the traditional RP-3 fuel to test the atomization character under the condition of different pressure and mixing proportion by laser test methods.
\end{abstract}

\section{Introduction}

Nowadays, demand for Aviation fuel has been increasing rapidly. Increasingly serious environmental problems, economic pressure, and oil supply problems appeared gradually. A series of kerosene alternative aircraft fuels, which can substitute the traditional aviation fuel, is arousing people's interest[1]. Extracted from biomass, natural gas and coal, a synthetic alternative fuel is considered a viable alternative aircraft fuel alternatives, because these kinds of fuel can be used in the existing aircraft engine fuel supply system and the fuel nozzle, and under the condition of the combustion chamber do not revise the application of alternative fuel. Fuel atomization performance plays significant role in aircraft engine combustion chamber, because atomization affects the efficiency of the combustion chamber, combustion stability and emissions significantly. So the aviation alternative fuel atomization performance, can effectively evaluate the applicability of the new airline alternative fuels for aviation engine combustion chamber, and for alternative fuel combustion performance and airworthiness provide important basis for the study[2].

For the purpose to test the availability of alternative fuel, it's necessary to test the atomization and spray characters, which are very important to the combustion performance[3]. The main method to test the atomization factors is PDA (Phase Doppler particle dynamic analyzer) and PIV (Particle image velocimetry) method, which are based on laser means. We utilize PDA method to test the SMD (Sauter Mean Diameter), which represents the atomization quality, by PDA apparatus. And then we use PIV method to test the velocity field distribution, which also very important to testify the quality of atomization and spray[4-5].

To test the applications of biomass alternative fuel in aircraft engine, the experiment mainly through mixing alternative fuels into traditional aviation kerosene according to certain proportion ratio[6]. So a problem emerge that we need to study how the mixing biomass alternative aircraft fuels influence the traditional jet fuel in atomization and combustion performance.

For the alternative fuel component is very complex, the influence of different components for atomization and combustion performance vary a lot. Our solution is to began experimental research by mixing each single component of alternative fuels into traditional RP-3 fuel, in order to pave a way for further research on the influence of varieties of biomass components to traditional fuel.

The objective of this paper is to test the influence of typical single component-kerosene C17 and C18 to the biofuel in atomization characters, such as SMD(Sauter mean diameter), Velocity distribution and spray cone-angle. 


\section{Experiment Setup}

Phase Doppler particle dynamic analyzer (PDA) aims at measuring liquid spray distribution of particle size and speed of 2-dimentional and 3-dimentional aspect, at present is the most advanced non-contact measuring instruments in the world. It derives from the 80s of the laser Doppler velocimetry (LDA) and can simultaneously measure the SMD and velocity distribution of gas-solid, gas-liquid, and liquid droplets in two phase flow field.

For the fuel spray field is axisymmetric, so this study only to spray axis along one side of the center of the radial measurement. The PDA test method is as follows:

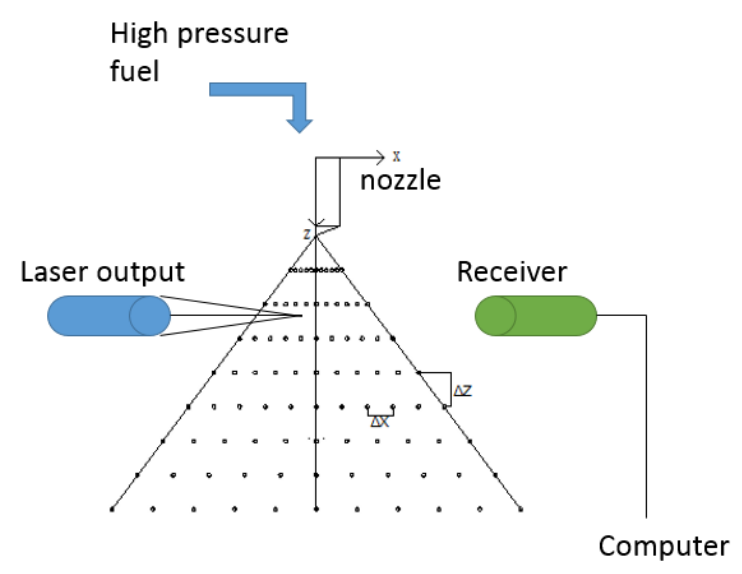

Fig. 1 SMD test by PDA measure method

Particle image velocimetry (PIV) aims to analysis the velocity distribution in the atomization field. The advantage of PIV method is to get the whole velocity distribution simultaneously. The PIV control software can calculate the velocity in the filed by the immediate movement of atomization, which provided by the adjacent pauses of sheet laser.The PIV experimental apparatus are as follows:

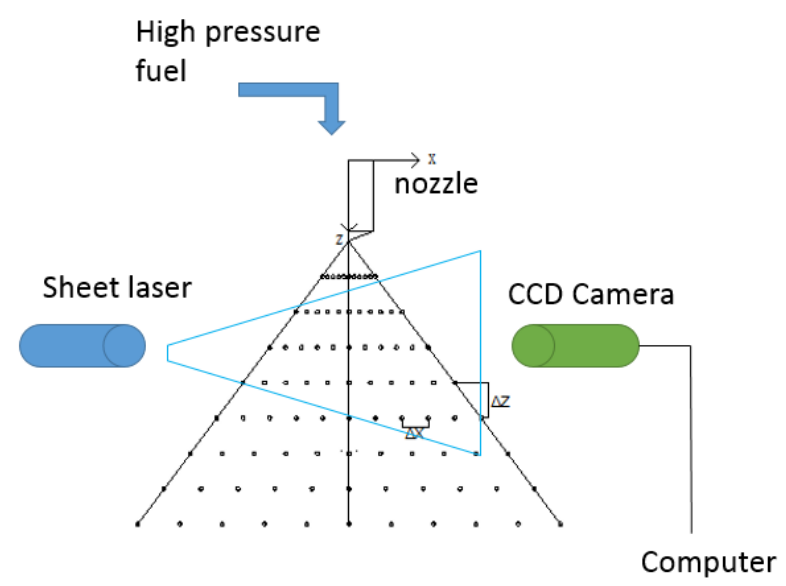

Fig. 2 Velocity distribution and spray cone-angle test by PIV measure method

\section{RESULTS AND DISCUSSION}

In order to test the SMD(Sauter mean diameter) influenced by the alternative fuel component, we adopt several points along with the atomization cone,and the coordinates of the points are as follows:

$\mathrm{X}=5 \mathrm{~mm} \mathrm{Y}=0 \mathrm{~mm} \mathrm{Z}=6 \mathrm{~mm}$

$X=10 \mathrm{~mm} Y=0 \mathrm{~mm} \mathrm{Z}=12 \mathrm{~mm}$

$X=15 \mathrm{~mm} \mathrm{Y}=0 \mathrm{~mm} \mathrm{Z}=18 \mathrm{~mm}$

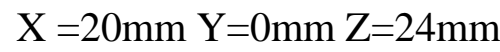

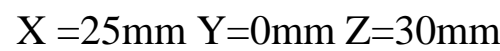


We will look into the SMD variation influenced by different pressure and different percentage of alternative fuel components, precisely, alkane C17 and C18.

\begin{tabular}{|c|c|c|c|c|}
\hline Proportion & Pressure/Mpa & $\mathrm{x} / \mathrm{mm}$ & $\mathrm{z} / \mathrm{mm}$ & SMD/um \\
\hline RP-3 & 0.3 & 5 & 6 & 59.8 \\
\hline RP-3 & 0.7 & 5 & 6 & 36.7 \\
\hline RP-3 & 1.1 & 5 & 6 & 18.7 \\
\hline 6\% C17 & 0.3 & 5 & 6 & 64.2 \\
\hline $6 \%$ C17 & 0.7 & 5 & 6 & 58.8 \\
\hline 6\% C17 & 1.1 & 5 & 6 & 52.2 \\
\hline 10\% C17 & 0.3 & 5 & 6 & 69.7 \\
\hline $10 \%$ C17 & 0.7 & 5 & 6 & 51.1 \\
\hline $10 \%$ C17 & 1.1 & 5 & 6 & 31.6 \\
\hline $6 \%$ C18 & 0.3 & 5 & 6 & 62.5 \\
\hline $6 \%$ C18 & 0.7 & 5 & 6 & 53.7 \\
\hline 6\% C18 & 1.1 & 5 & 6 & 43.6 \\
\hline $10 \%$ C18 & 0.3 & 5 & 6 & 67.3 \\
\hline $10 \%$ C18 & 0.7 & 5 & 6 & 55.6 \\
\hline $10 \%$ C18 & 1.1 & 5 & 6 & 42.2 \\
\hline
\end{tabular}

Table. 1 SMD distribution at $\mathrm{X}=5 \mathrm{~mm} \mathrm{Z}=6 \mathrm{~mm}$

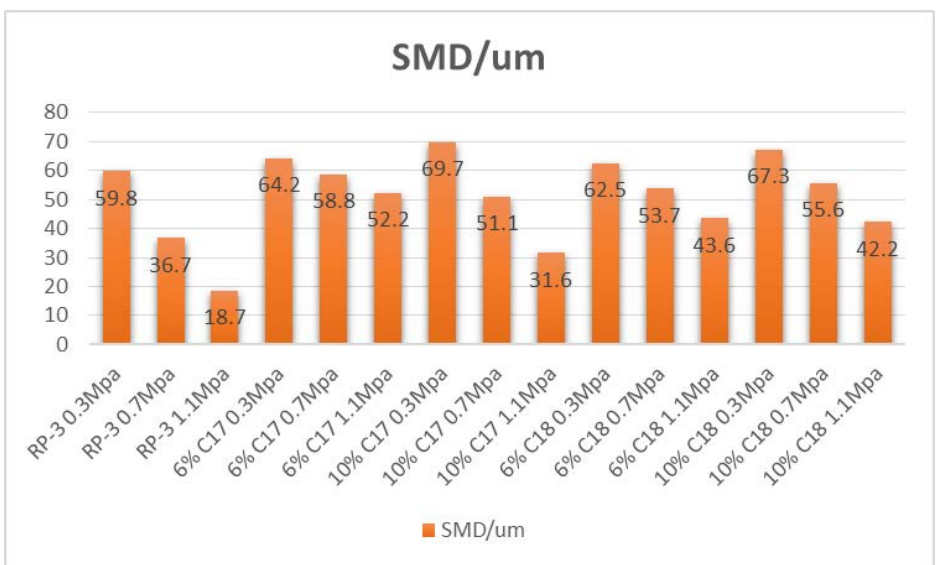

Fig. 3 SMD distribution at $X=5 \mathrm{~mm} Z=6 \mathrm{~mm}$

According the result above, we can discover that at position $X=5 \mathrm{~mm} Z=6 \mathrm{~mm}$. Direct at one kind fuel, the Sauter mean diameter decline obviously when pressure rise, and compared with traditional RP-3 jet fuel the SMD rise a bit when mixing proportion rise by $6 \%$ and $10 \%$

From the result we can infer that The pressure influence the atomization much, and the mixing proportion of alternative fuel also influence the atomization quality by SMD value.

For the position at $X=X=10 \mathrm{~mm} Z=12 \mathrm{~mm}, X=15 \mathrm{~mm} \mathrm{Z}=18 \mathrm{~mm}, X=20 \mathrm{~mm} \mathrm{Z}=24 \mathrm{~mm}, X=25 \mathrm{~mm}$ $\mathrm{Z}=30 \mathrm{~mm}$, we can also draw a same conclusion that the Sauter mean diameter raises when pressure drop and mixing proportion rise, regardless of the position in the atomization field.

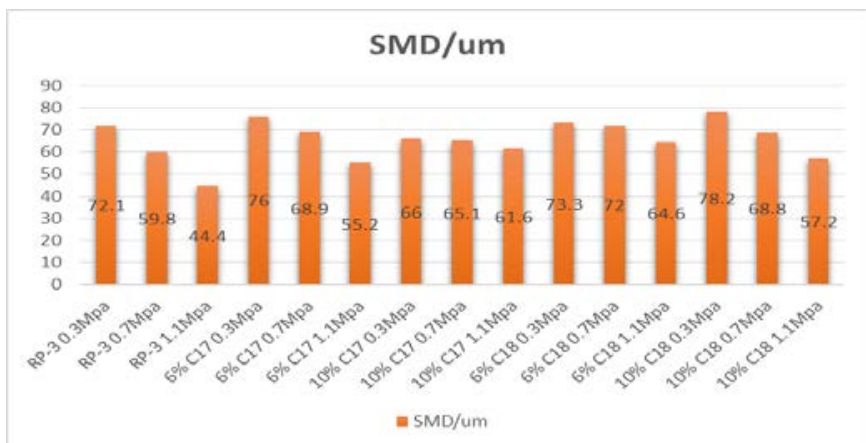

Fig. 4 SMD distribution at $X=10 \mathrm{~mm} Z=12 \mathrm{~mm}$ 


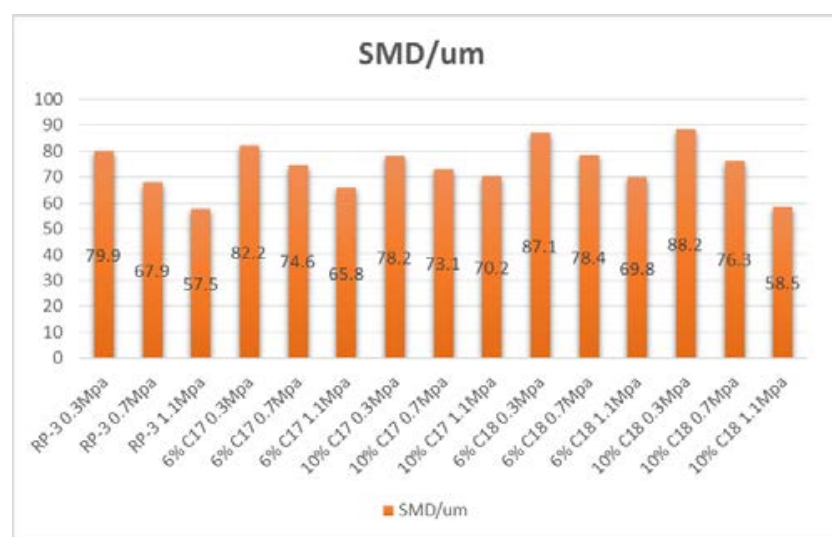

Fig. 5 SMD distribution at $X=10 \mathrm{~mm} Z=12 \mathrm{~mm}$

Our another work is to get the PIV image to analysis the whole velocity distribution in the atomization field, we grasp the PIV image and adopt the Image as follows

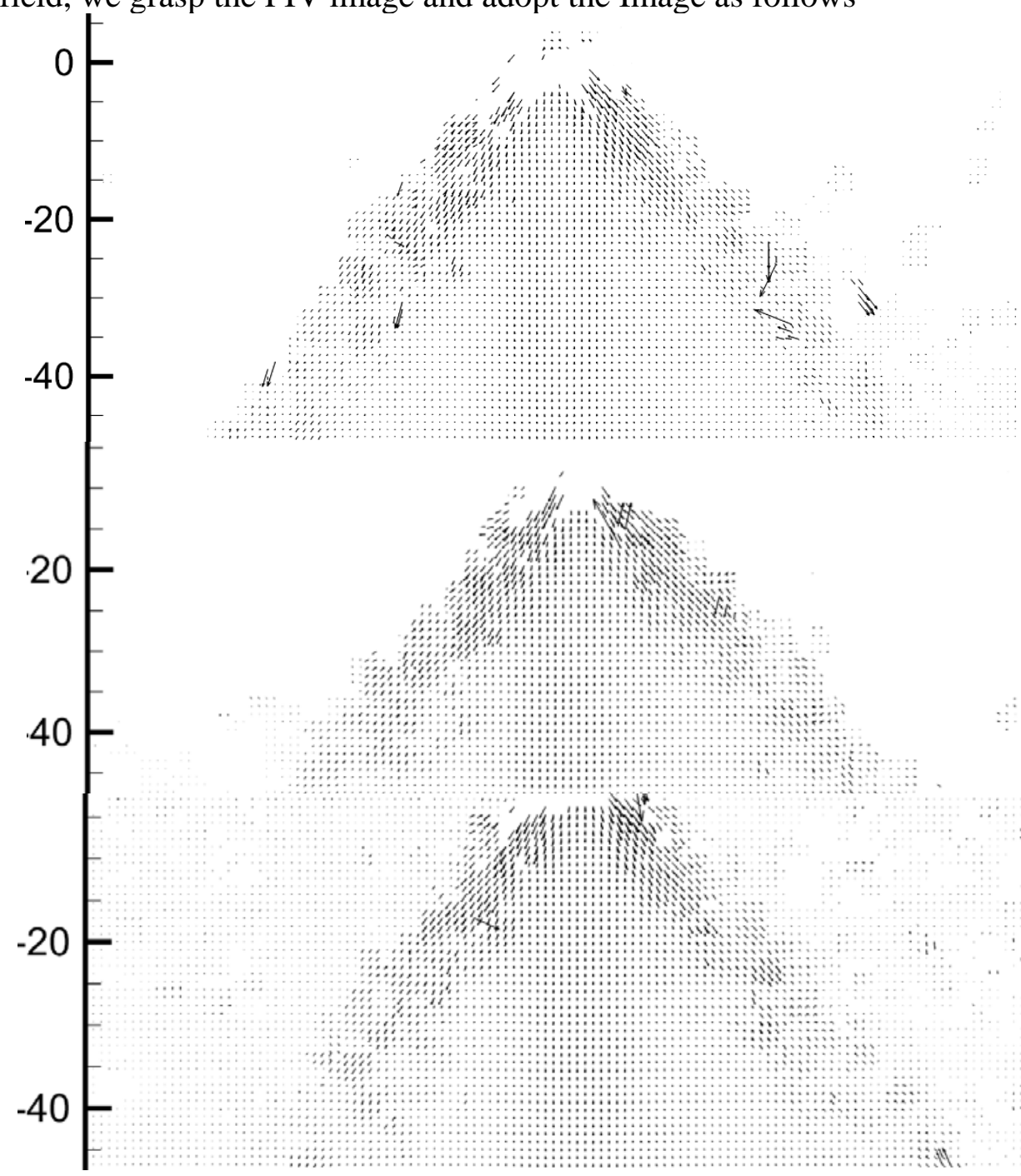

Fig. 6 The velocity distribution of RR-3 1.1Mpa, 10\% C17 1.1Mpa and 10\% C18 1.1Mpa

From the paragraph we can watch the whole velocity distribution and the cone-angle. For the velocity, we can observe that the drop with large velocity accumulate alone the conical surface, and the cone-angle only Reflect a small change, just about 1-2 degree.

\section{Summary}

From this research we can draw a conclusion that the linear chain alkane in the alternative biofuel have influences in the atomization character, especially in the Sauter mean diameter, and have little 
effect in the velocity distribution and cone-angle. These atomization characteristics should be taken into account in the aircraft engine design and further research on combustion character of alternative biofuel .

\section{References}

[1]Blakey, S., Rye, L., and Wilson, C. W., Aviation gas turbine alternative fuels: A review, Proc.Combust. Instit., vol. 33, no. 2, pp. 2863 - 2885, 2010.

[2]A. Lefebvre, Gas Turbine Combustion, Hemisphere Publishing Corp., 1983.

[3]L. Gardner, R.B. Whyte, Gas Turbine Fuels, in: Design of Modern Turbine Combustors, Academic Press Ltd.

[4]F.E. Armstrong, J.E. Allen, R.M. Denning, Proc. IMechE G 211 (1997).

[5]F. Behrendt, Y. Neubauer, M. Oevermann, B.Wilmes, N. Zobel, Chem. Eng. Technol. 31 (5)(2008) $667-677$.

[6]J.G. Speight, The Chemistry and Technology of Petroleum, fourth ed., CRC Press, New York, 2006. 